\title{
Disseminated herpes simplex in newborn infants
}

\author{
T. BIRD, J. E. ENNIS, A. J. WORT, AND P. S. GARDNER \\ From the Department of Pathology, Newcastle General Hospital, \\ and Dryburn Hospital, Durham, and the Department of Bacteriology, \\ Royal Victoria Infirmary, Newcastle upon Tyne
}

SYNOPSIS Six cases of disseminated herpes simplex virus infection in newborn infants have been collected. The morbid anatomical and histological findings are described for the various tissues of the body. For the first time, the typical lesions were found in the lung. This and the other findings are discussed from the aetiological point of view.

Infection by herpes simplex virus may present in a number of different ways. Usually the primary infection takes the form of a relatively mild lesion affecting the mucous membranes but several more severe forms are recognized. Among these are such conditions as eczema herpeticum and herpes encephalitis. A third form affecting, as far as we know, only the newborn infant, was first described by Hass in 1935 and called by him "hepato-adrenal necrosis'. On histological grounds he associated the condition with infection by herpes simplex, although virological proof was lacking at that time. Subsequent authors (Zuelzer and Stulberg, 1952; France and Wilmers, 1953; McDougal, Beamer, and Hellerstein, 1954; Pugh, Newns, and Dudgeon, 1954; Colebatch, 1955; Williams and Jack, 1955; Bird and Gardner, 1959) have accepted this and in some cases have recorded isolation of the virus from affected organs. Quilligan and Wilson (1951) reported a case of neonatal liver necrosis and skin lesions from which herpes simplex virus was isolated. They thought an encephalitis was probably present.

In this paper we report six cases in which hepatoadrenal necrosis has been demonstrated. Herpes simplex virus was isolated in the four cases in which isolation was attempted. Our purpose in reporting these cases is to emphasize that this is by no means as unusual a condition as was once believed. We also believe that certain of the pathological features demonstrated may throw new light on the mode of infection and spread of this condition.

\section{CASE REPORTS}

CASE 1 A female infant (birth weight $10 \mathrm{lb}$.) was admitted to hospital at the age of 13 days; she had been

Received for publication 23 October 1962 born at home after a normal pregnancy and delivery. A week before the birth her sister, aged 15 months, had developed painful white ulcers on the mouth and tongue and on the day of delivery the mother herself had similar lesions. On the seventh day of life the infant, who had been well until this time, became less lively and did not feed well from the breast. The next day she was transferred to bottle feeding and the midwife called in the family doctor, who initiated treatment with tetracycline. During the following $\mathbf{4 8}$ hours her condition improved slightly, although her temperature remained at $100^{\circ} \mathrm{F}$. On the twelfth day she passed some altered blood in her stool and next day was admitted to hospital.

At the time of admission she was found to be lethargic; there was slight cyanosis and moderate jaundice. The liver was palpable at the umbilicus but there was no splenomegaly. No lesions affecting the skin or mucous membranes were seen and the cerebrospinal fluid was normal. She was nursed in an oxygen tent and treated with intramuscular streptomycin. She continued to feed poorly and at intervals regurgitated blood unmixed with stomach contents, suggesting the diagnosis of oesophageal ulceration. In the 36 hours following admission the child's condition deteriorated and she died at the age of 14 days.

Necropsy was carried out five hours after death. There was cyanosis of the lips and slight jaundice. No ulcerated lesions of the skin or mucous membranes were present. Internal examination revealed ulceration of the lower third of the oesophagus and pulmonary congestion with a single haemorrhagic lesion in the left lower lobe. The heart showed no abnormality apart from pallor of the myocardium. Striking changes were, however, seen in the liver, which weighed $200 \mathrm{~g}$. It showed a reddish mottled appearance with many greyish spots each about $1 \mathrm{~mm}$. in diameter. These were visible both externally and on section.

The large and small intestines both contained much altered blood and the adrenal, when sectioned, showed many small haemorrhages.

Histological examination of the liver and adrenal showed a remarkable degree of necrosis with significant 
changes in those cells which remained. Appearances in these were variable: some were multinucleate, others showed eosinophilic inclusions whilst the typical peripheral beading of the nuclear chromatin was present in many more. Frozen sections stained with Sudan IV showed considerable amounts of lipid in the necrotic cells.

The adrenal showed extensive necrosis with the presence of intranuclear inclusion bodies. The whole process appeared to be less advanced than in the liver. Herpes simplex virus was isolated from adrenal and liver tissue taken at necropsy.

CASE 2 This female infant was born in a nursing home after a long labour terminating in a forceps delivery. The matron of the nursing home, who attended at the time of the delivery, had a heavy cold.

The infant made satisfactory progress until the fourth day of life, when she became pale, began to breathe heavily and bring up a lot of mucus.

On admission to hospital she was dyspnoeic, frothing at the mouth, and had a mucoid nasal discharge. Clinical examination revealed a few rhonchi at the lung bases but no other significant findings. The liver was not enlarged. Treatment with penicillin and streptomycin was started but the chest signs became more pronounced and after an initial improvement she collapsed and died on the ninth day.

Necropsy was performed 36 hours later. There was slight cyanosis but no obvious jaundice. The lungs were congested and slightly oedematous. The larger bronchi of the lower lobes contained mucopus and the smaller bronchi were filled with plugs of firm yellowish material. The liver again showed the characteristic picture of diffusely scattered foci resembling miliary tubercles. In this case no macroscopic changes were noted in the adrenals.

Histological examination of the liver showed many necrotic foci which in some areas had become confluent. Finely divided fat was present in surviving cells but there were no inclusion bodies. The adrenal glands showed extensive necrosis and some haemorrhage in the foetal cortex. Occasional inclusion bodies were seen. There was a well-marked tubular necrosis in the kidney, and the collecting tubules showed granular eosinophilic material.

The lung showed several unique features. There were areas of peribronchial necrosis (Fig. 1) and changes in the bronchial epithelium (Fig. 2a) which were reminiscent of those seen in herpetic lesions of the skin. No inclusion bodies have so far been demonstrated but the empty nuclear envelopes which were present at the edges of the lesion were probably due to herpes simplex virus infection. Elsewhere, in the lung alveoli, where definite bronchopneumonia had occurred, it was possible to demonstrate classical herpes simplex virus inclusions (Fig. 2b).

CASE 3 This baby, a male, was born at home after a normal pregnancy and delivery; his birth weight was $6 \frac{3}{4} \mathrm{lb}$. The maternal grandmother, who lived in the house,

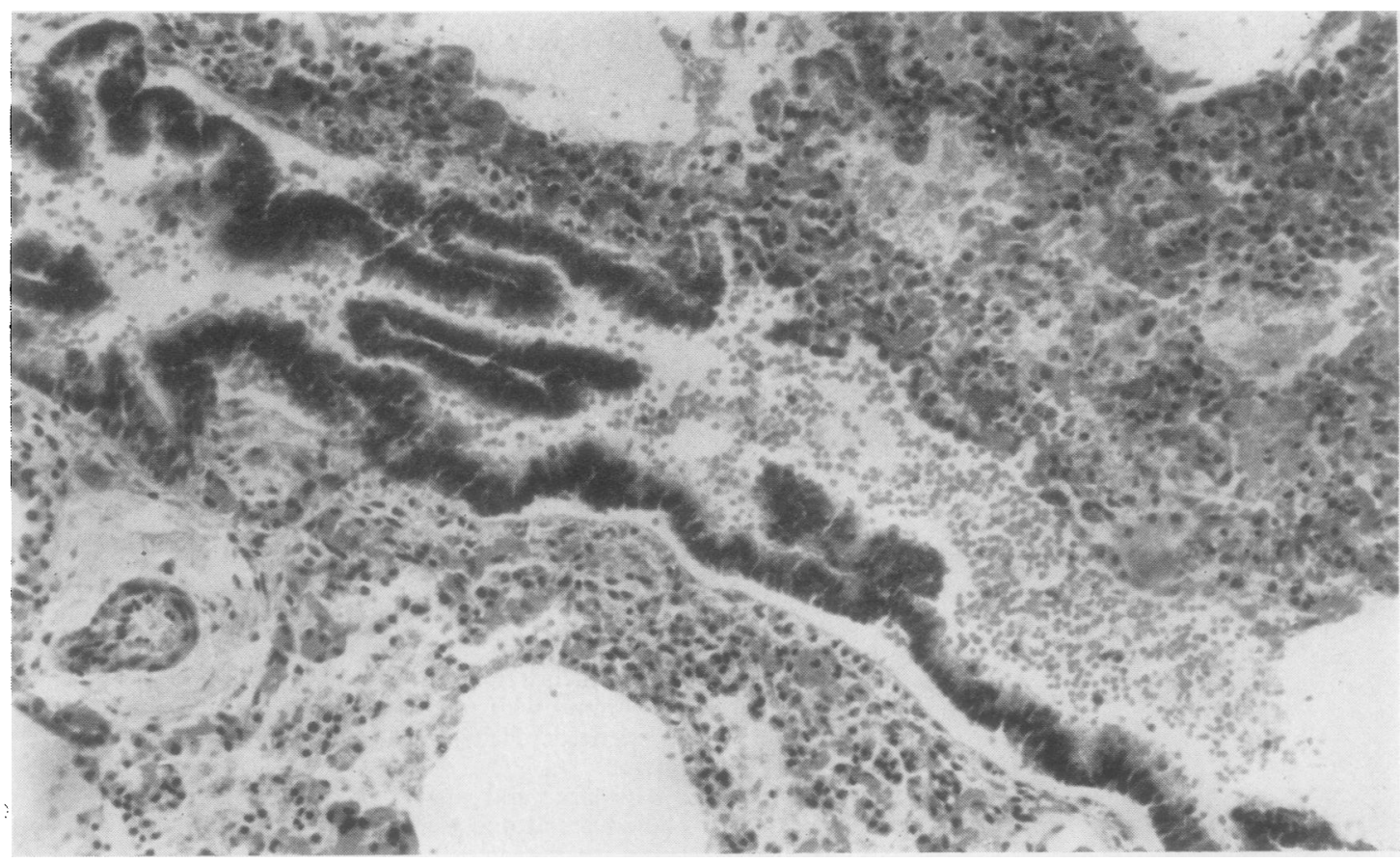

FIG. 1. Lung (case 2) showing necrosis involving terminal bronchiole and loss of bronchiolar epithelium. Haemato$x y$ lin and eosin $\times 300$. 


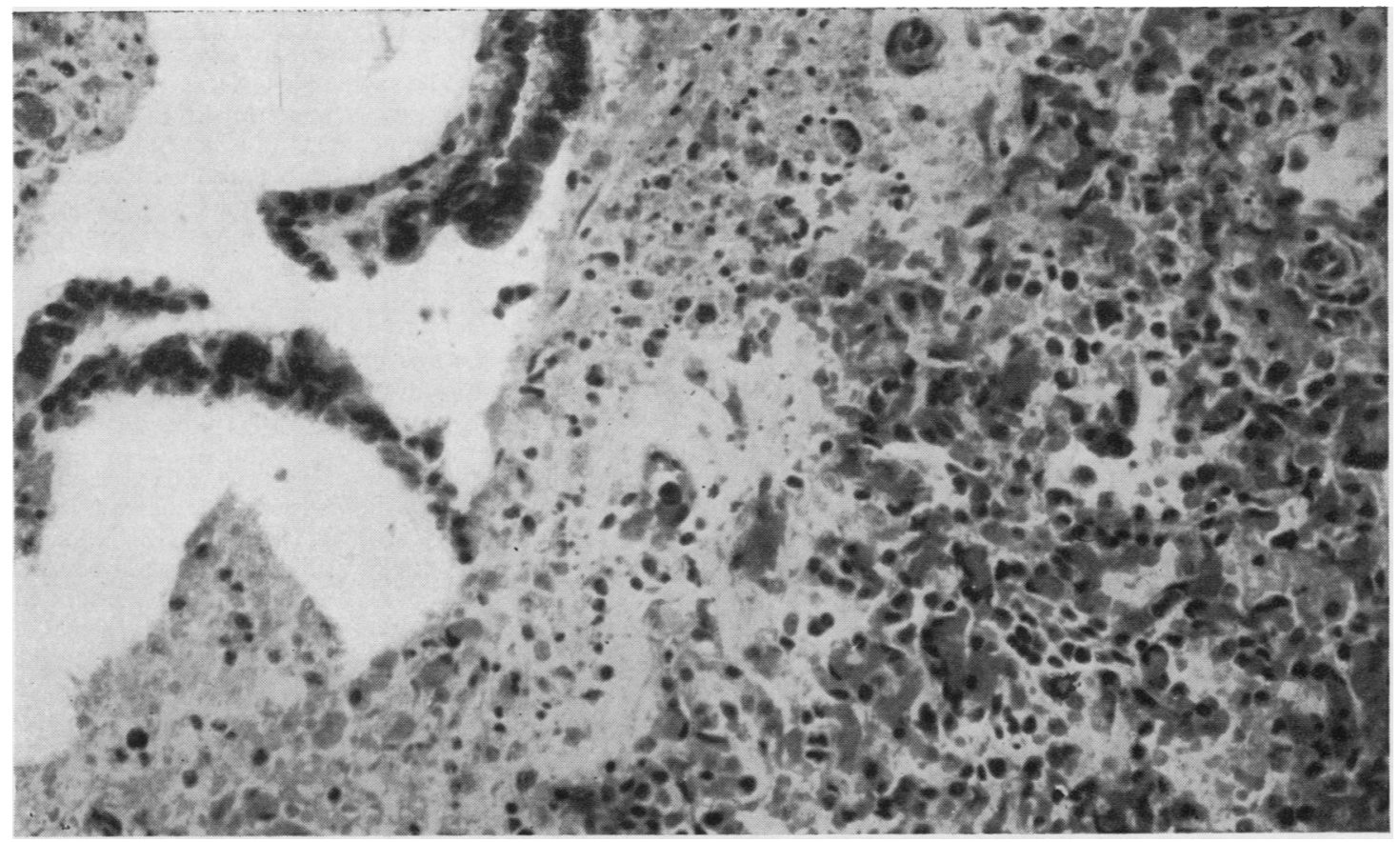

FIG. 2a. Lung (case 2) showing peribronchiolar necrosis and epithelial changes due to herpes simplex. Haematoxylin and eosin $\times 480$.

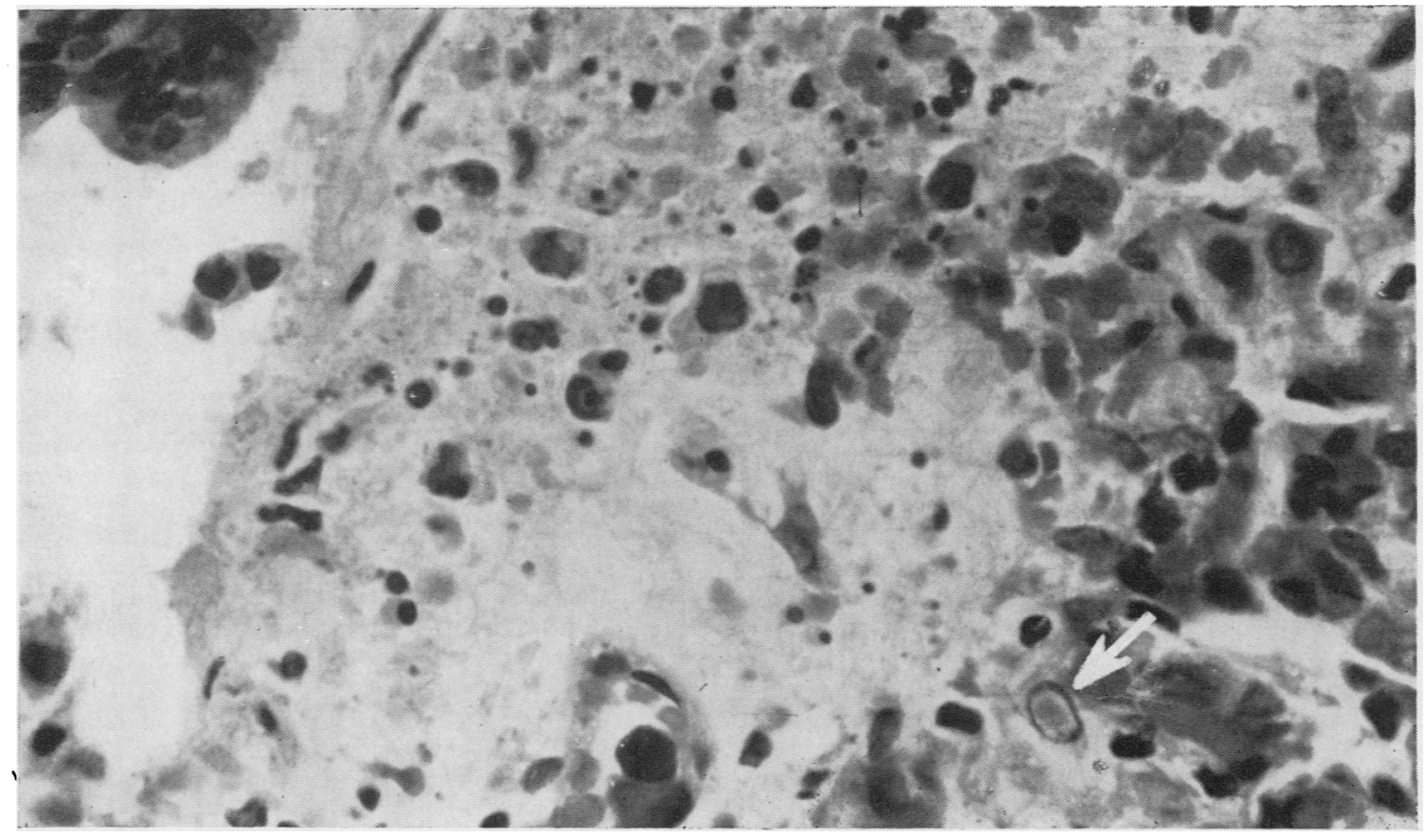

FIG. 2b. - High-power view of centre portion of Fig. $2 a$ showing necrosis and an inclusion body due to herpes simplex. Haematoxylin and eosin $\times 1,200$. 


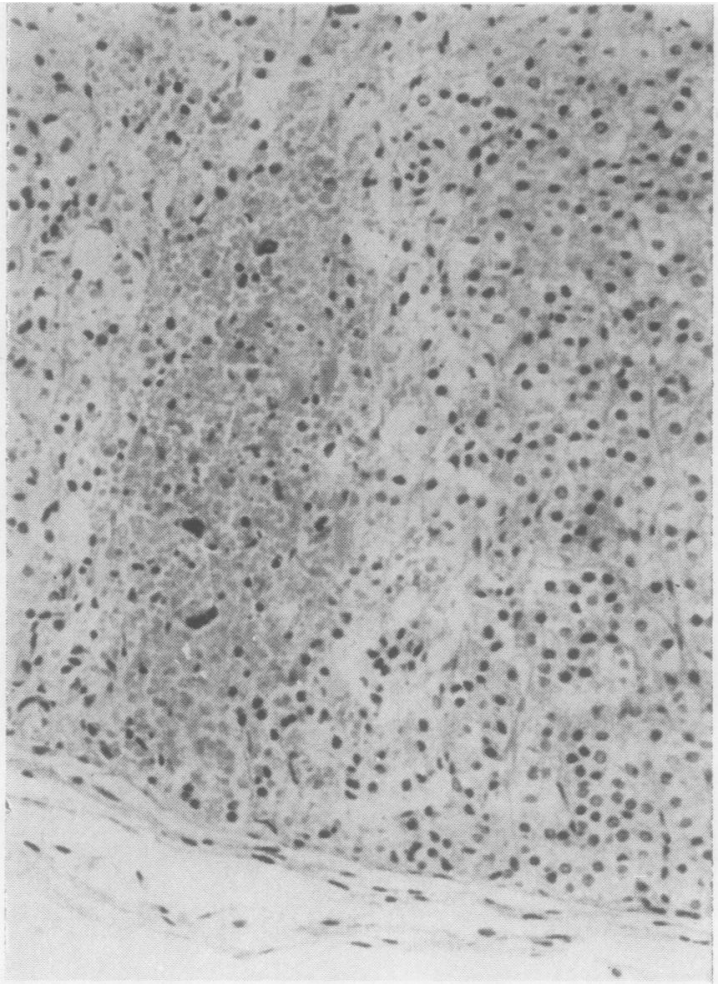

FIG. 3. Adrenal gland showing the areas of necrosis which are typical of disseminated herpes simplex. Haematoxylin and eosin $\times 120$

had a sore spot on her lip three weeks before the birth and again four days after the delivery. Artificial feeding was begun 24 hours after birth and the baby progressed favourably for the first few days of life.

On the tenth day, however, the urine became dark yellow and two days later there was definite jaundice. The stools, which previously were of normal colour, had now become grey. On the fourteenth day he was admitted to hospital because the jaundice had become deeper and he was very ill and lethargic.

Clinical examination showed a few erythematous spots and the umbilicus was moist and covered with bloodstained crusts. The abdomen was distended and the liver, which was very firm with a well-defined edge, was palpable three fingerbreadths below the costal margin.

While blood was being taken for examination the child had a generalized convulsion and 10 hours after admission he collapsed and died.

Examination of this blood gave the following results: Hb 15.6 g. $/ 100 \mathrm{ml}$. (106\%); W.B.C. 11.200 c.mm.; direct Coombs test, negative; serum bilirubin $12.2 \mathrm{mg} . / \mathrm{ml}$.; alkaline phosphatase 26 units (King-Armstrong); serum proteins $5.2 \mathrm{mg} . / \mathrm{ml}$. (albumin 3.3 , globulin 1.9); thymol turbidity, thymol flocculation, and zinc sulphate turbidity negative; blood urea $34 \mathrm{mg} . / \mathrm{ml}$.; S.G.O.T. and S.G.P.T. 3,680 and 2,760 Sigma Fraenkel units respectively.
Necropsy was performed 11 hours after death and showed a well-nourished baby with severe jaundice and occasional petechial haemorrhages.

The internal appearances were similar to those previously described and subsequent histological examination confirmed the presence of focal necrosis with inclusion bodies in the liver and adrenal gland (Fig. 3). Herpes simplex virus, on this occasion, was isolated from the blood taken before death.

CASE 4 This male infant, of birth weight $8 \mathrm{lb} .4 \mathrm{oz}$., was delivered by elective caesarean section at term. There had been mild toxaemia during the pregnancy and the mother had had a previous abortion at eight weeks but had one other live child.

Progress was satisfactory until the fifth day, when the baby was found to be lethargic and to have a rectal i temperature of $103^{\circ} \mathrm{F}$. Although there was no evidence $\hat{\omega}$ of sepsis, treatment with penicillin and streptomycin was 음 begun but, later that day, the baby's condition deteriorated further. There was hepatomegaly and other signs of $\vec{\oplus}$ cardiac failure. Treatment with digoxin and oxygen led $\mathbb{D}$ to a temporary improvement and lumbar puncture produced a clear, colourless cerebrospinal fluid. Hepatomegaly persisted and on the ninth day the liver was palpable two fingerbreadths below the costal margin. When out of oxygen the baby was cyanotic and this was especially marked after feeding. On the evening of the $\omega$ ninth day the baby showed hypertonia of all limbs and was excessively restless. Death occurred on the eleventh day.

Necropsy on the following day showed a pale cyanosed infant with some subcutaneous oedema. The liver was grossly enlarged, weighing $180 \mathrm{~g}$., and the presence of the miliary foci previously described was again noted. Similar miliary necrotic areas were seen in the adrenals and there was inflammation of the oesophagus.

Histological examination of the liver showed inclusion bodies which were considered to be typical of herpes simplex virus.

CASE 5 This case has been reported in full elsewhere (Bird and Gardner, 1959) and only a brief note will now be included. He was a full-term male infant, 'delicate' from birth, who collapsed on the twenty-first day of life, and died within three hours of admission to hospital. Before death it was noted that he had an enlarged liver and spleen; there was a blister on the back but no jaundice.

The liver was enlarged and showed small areas of $\Omega$ necrosis. Similar lesions were seen in the adrenals. N Large areas of confluent necrosis and typical herpes $N$ simplex inclusion bodies were seen histologically. The $\sigma$ virus was isolated from the liver in this case.

CASE 6 This male child was admitted to hospital at the age of 9 days. He had been born at home after a normal pregnancy and delivery. Birth weight was $7 \mathrm{lb} .2 \mathrm{oz}$. Three days before delivery, however, the mother had complained of a sore throat and mouth. This had become worse by the time of the delivery and on the next day her mouth was ulcerated. 


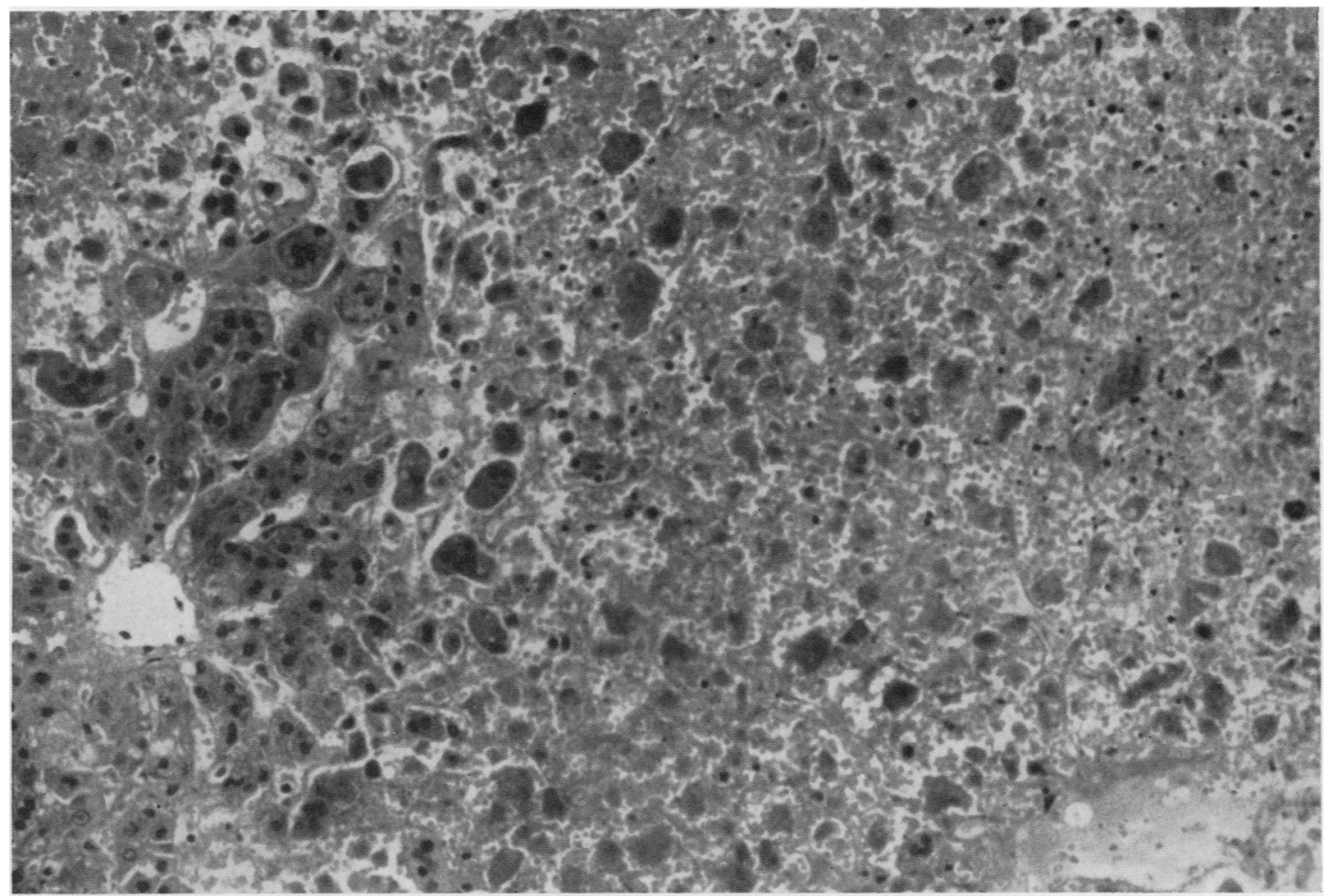

FIG. 4. Liver (case 6) showing extensive necrosis, inclusion bodies, and multinucleate cells. Haematoxylin and eosin $\times 300$.

On the fifth day the infant became sleepy and was awakened with difficulty. He was seen at home by a paediatrician and treatment with Achromycin begun. There was, however, no improvement and on the ninth day he was admitted to hospital. He was found to have a temperature of $101.4^{\circ} \mathrm{F}$. and some umbilical sepsis. A swab was taken and a growth of coagulase-negative staphylococci was obtained. The liver and spleen were not palpable and the baby's haemoglobin was $19 \cdot 2$ g. $/ 100 \mathrm{ml}$. $(118 \%)$ and the white cell count was $7,800 / \mathrm{c} . \mathrm{mm}$. Two days later jaundice appeared and on the morning of the seventeenth day the left side of the face began to twitch. The child died shortly afterwards.

Post-mortem examination on the following day showed a mature male infant weighing $6 \mathrm{lb} .1 \mathrm{oz} .(2.75 \mathrm{~kg}$.) and measuring 22 in. $(55 \mathrm{~cm}$.).

Internal examination showed the same striking lesions in the liver, but apart from some areas of consolidation in the lungs there was little else of note macroscopically.

Histological examination of various tissues showed the lesions which we have now come to regard as characteristic, and Fig. 4 shows the appearance of the liver, whilst the typical adrenal lesions as shown in Fig. 3 were present. In sections from this case we were able to follow the development of the inclusion from the very early stage seen in Figure 5a to the late form seen in Figure 5d. When sections of various tissues, stained with haematoxylin and eosin, were examined carefully with a high- resolution oil-immersion lens it was possible to demonstrate distinct differences between the morphology of the inclusion as seen in the liver and adrenal gland. In its early stage in the liver the nucleus first showed a tendency to swell and the chromatin to condense on the nuclear membrane. This was best seen when focusing on the top surface of the infected nucleus. Later the nucleoprotein became mauve and tended to shrink away from the nuclear membrane and eventually a definite annular form (Fig. 5b) could be seen. At this stage the inclusion bodies were distinctly eosinophilic. The last stage (the well-defined Cowdry type A inclusion) followed on quite closely (Fig. 5c). The final collapse of the nuclear membrane and loss of the contents are seen in Figure 5d.

Many of the affected cells in the liver were multinucleate and it is perhaps permissible to speculate as to what had actually occurred. It seemed likely that in this instance the multinucleate cells had been infected while they were actively dividing in an attempt to replace cells already destroyed by the virus. This hypothesis was borne out by the fact that many of the early forms were seen in such multinucleate cells.

The adrenal cells underwent a similar early stage, although here it was less well defined. The late stage shown in Fig. 6 consisted of particles of dense eosinophilic material grouped in aggregates reminiscent of a raspberry and occupying most of the nucleus.

The connective tissue of the capsule and small blood 


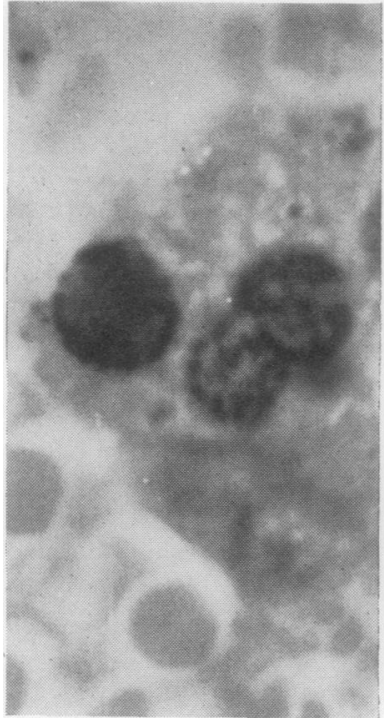

a

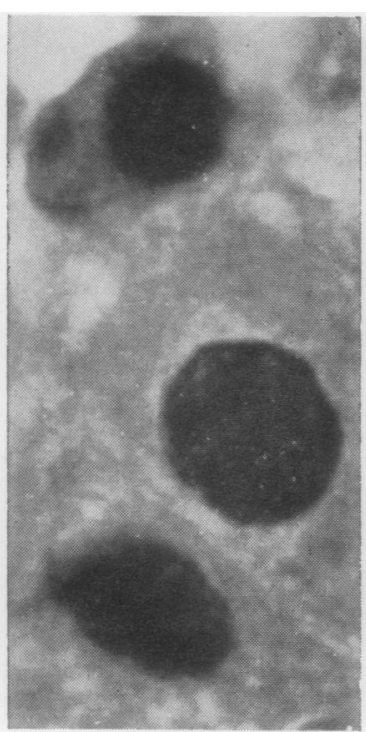

b

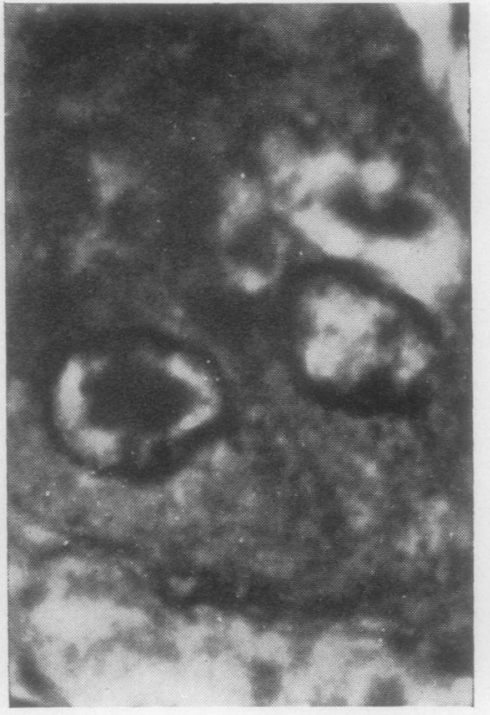

c

FIG. 5. Liver cells infected with herpes simplex. Haematoxylin and eosin $\times 1,500$ oil immersion.

a Multinucleate cell showing beading of nuclear membrane. b A later stage in which the nucleus is opalescent ando amphophilic. The nuclear material has not yet shrunk away from the membrane. c Well-developed annular type of inclusion body (Cowdry type A). d The empty nuclear membrane section.

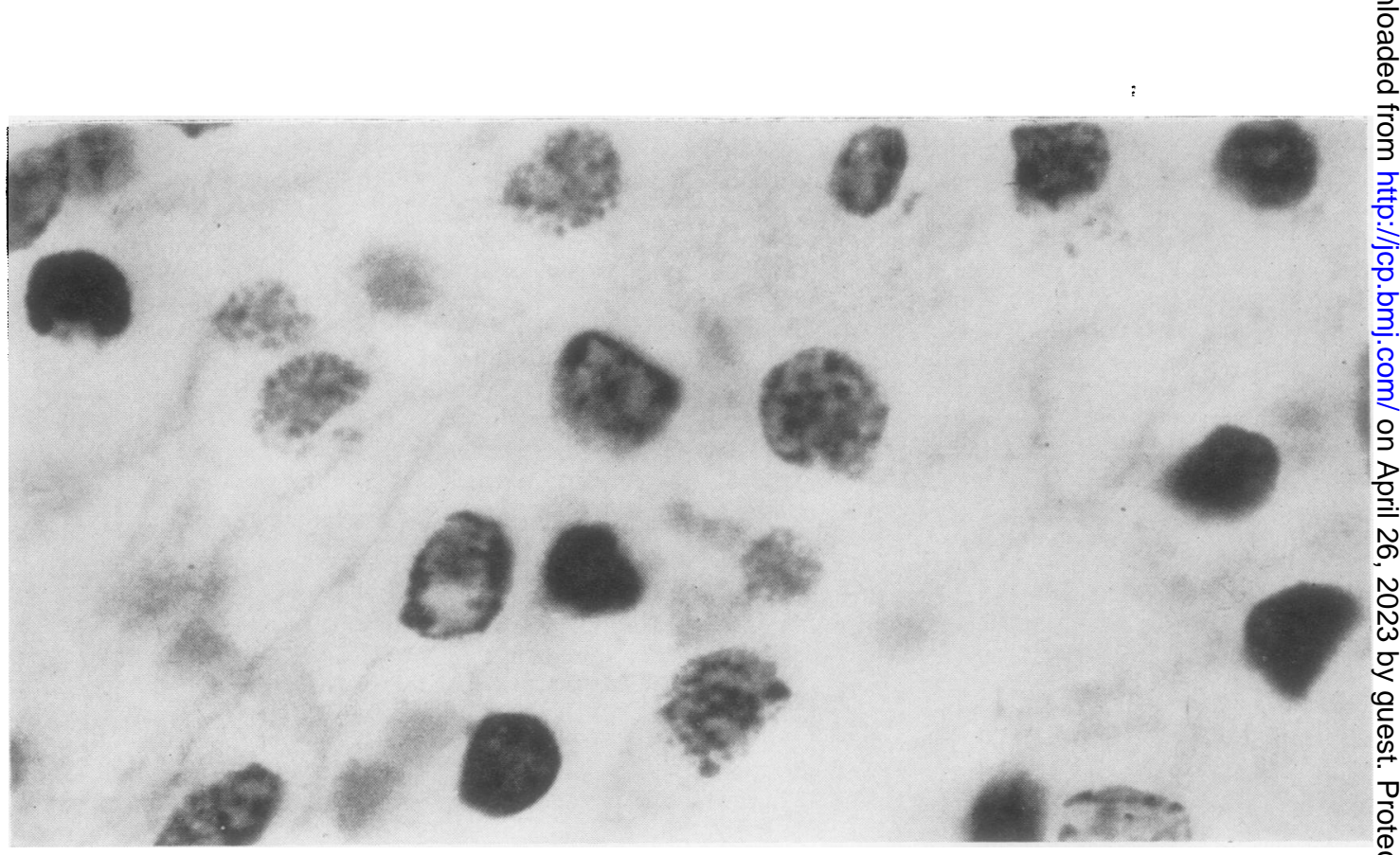

FIG. 6. Adrenal gland showing the particulate nature of the fully developed inclusions which are deeply eosinophilic $\frac{\rho}{\mathrm{D}}$ Haematoxylin and eosin $\times 1,500$ oil immersion. 


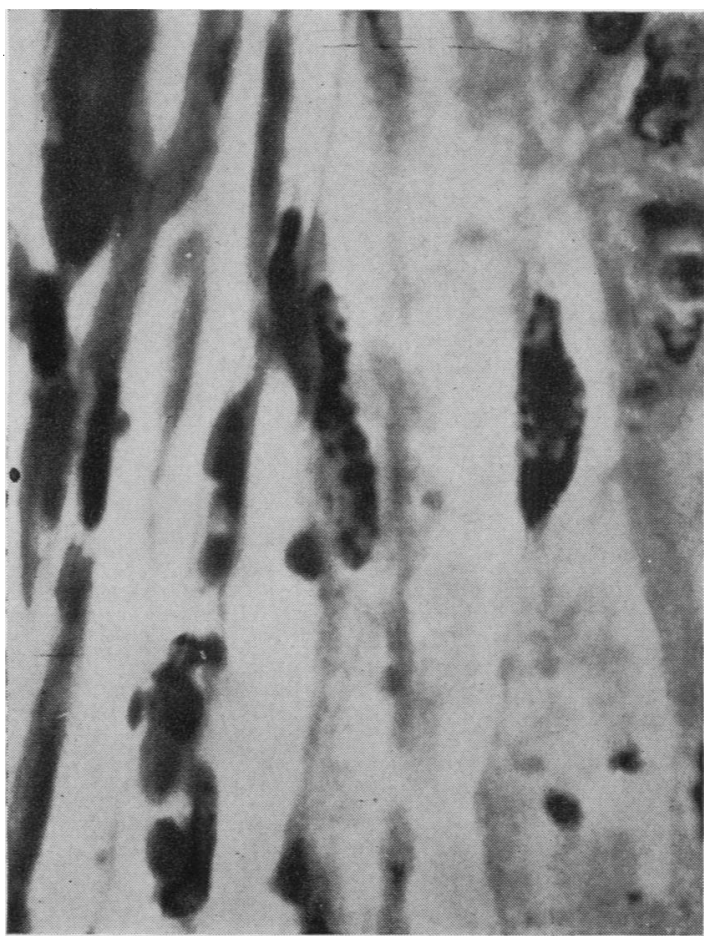

FIG. 7. Periadrenal connective tissue showing herpes simplex inclusion within the cell. Note the particulate appearance of the inclusions which are strongly eosinophilic. Haematoxylin and eosin $\times 1,500$ oil immersion. vessels of the adrenal gland as well as the septa were affected by herpes simplex (Fig. 7), but while the tunica media of small vessels were affected, we did not find any inclusions in the actual endothelium.

Inclusion bodies were also found in the spleen (Fig. 8). Other organs showed no significant change and in spite of an extensive search no inclusion bodies were found in the brain.

Herpes simplex virus was recovered from the adrenal and the liver in this case.

\section{DISCUSSION}

We consider that the diagnosis of disseminated herpes simplex has been firmly established in all six cases: in four by the combination of morbid anatomy and histology with virus isolation either from the tissues taken at necropsy or from the blood, and in the remaining two by the clear demonstration of typical inclusion bodies in the histological sections.

Once these very distinct appearances have been recognized the diagnosis is relatively simple. The paediatrician, on the other hand, is confronted with a different problem, since the early symptoms are ill defined. In an attempt to throw some light on the natural history of this condition, we have prepared Table I, in which the onset of the disease, the day on which symptoms appeared, and the day of death have been correlated.

It will be seen that where the history is clear the onset has been about the fifth day and that the cases

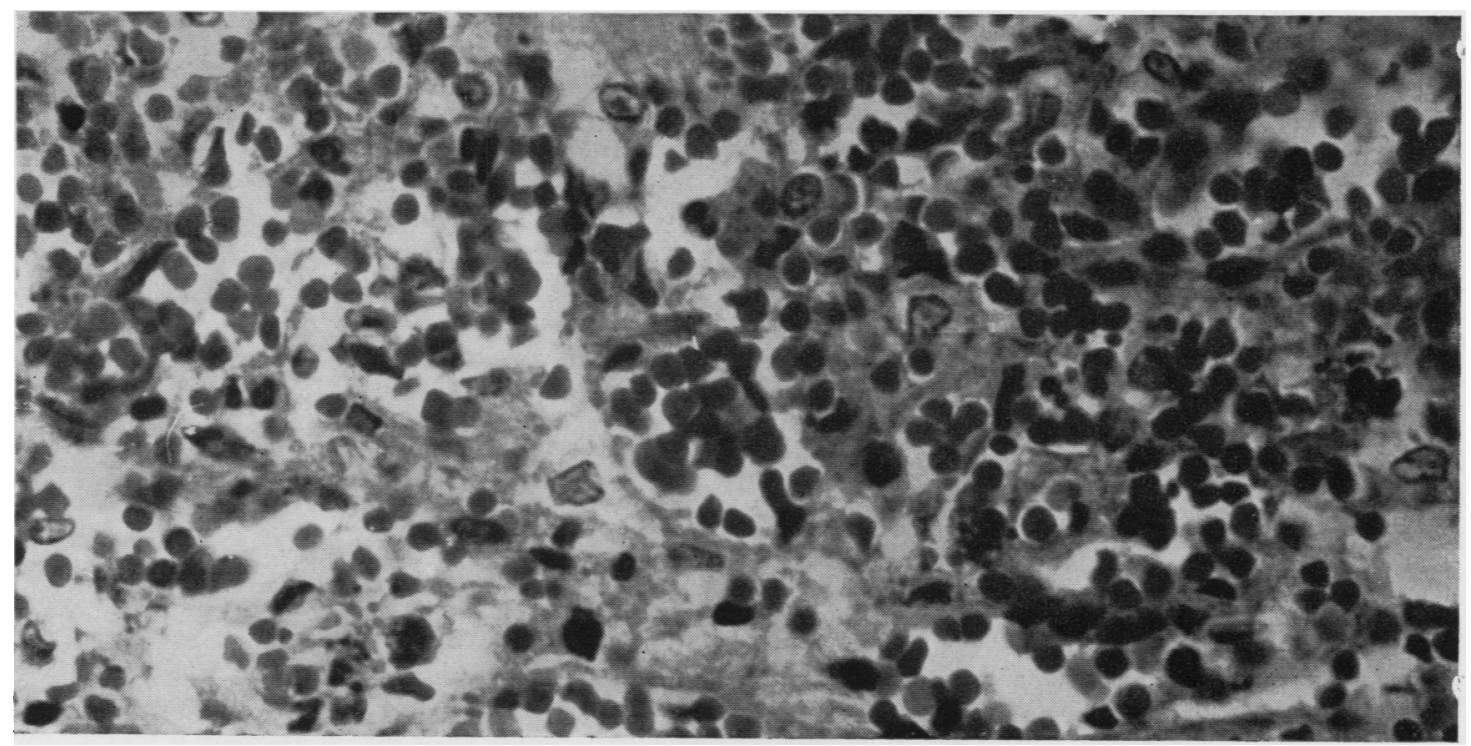

FIG. 8. Spleen (case 4) showing inclusion bodies due to herpes simplex. Haematoxylin and eosin $\times 800$. 
TABLE I

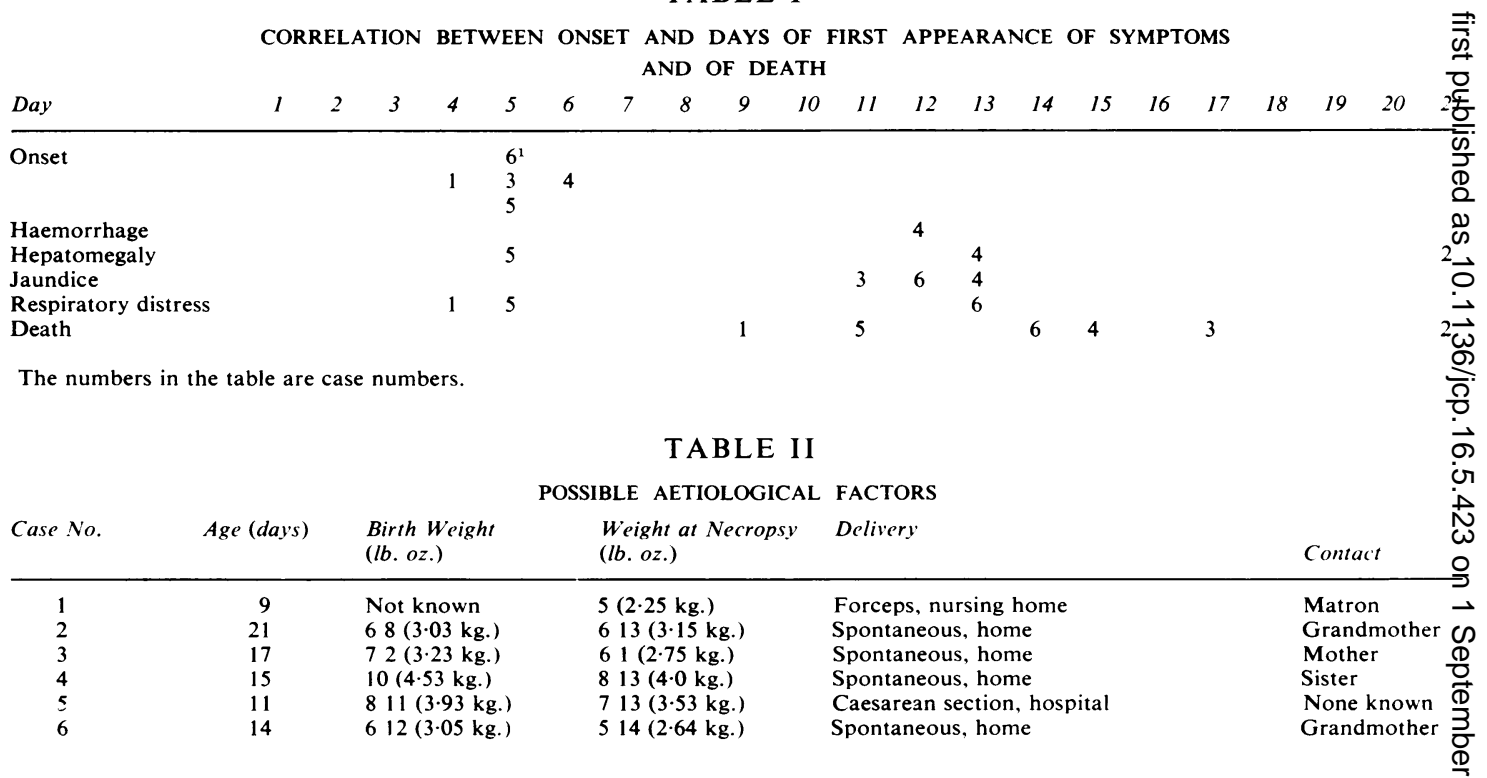

in which the symptoms were primarily respiratory have progressed rapidly. The cases in which respiratory tract infection was not a prominent feature have a slightly longer course but even so death occurred within 21 days. The paramount feature is the constant occurrence of severe liver disease, and it would seem that this condition should be considered whenever jaundice or other manifestations of liver disease arise in the second week of life. So far there are no recorded cases of survival of infants affected by this condition. On the whole this pattern of events is very similar to that described by many, including Colebatch (1955) and Zuelzer and Stulberg (1952), the only previous workers to collect a series of cases. Numerous attempts have been made to define the aetiology of the disease and various factors such as prematurity, malnutrition, and stress at the time of birth have been suggested (McKenzie, Hansen, and Becker, 1959; Zuelzer and Stulberg, 1952).

In Table II we have recorded some of the factors in our series. The factor to which we attach importance is that in five cases there was a definite close contact with overt herpetic infection of some form.

The demonstration of herpetic inclusions in the lung of case 1 , together with epithelial necrosis in the bronchi, is the first demonstration in the human infant of infection by this route and shows a close parallel with the careful experimental studies of Slavin and Berry in 1943. However, in view of the absence of such lesions in other cases it seems necessary to postulate a second portal of entry and, having regard to the experimental evidence of thesE authors (Slavin and Berry, 1943) and our oweE unpublished observation that intraperitoneal inocit lation in suckling mice will produce an almos $\Phi$ identical picture, we are inclined to the view that the umbilical cord can act as such a portal. The third possiblity is that the infant actually swallow the virus and it reaches the liver along the portaf vein. This hypothesis is supported by the reports $\bar{\sigma}$ ulceration in the oesophagus and by the fact that the liver is always severely damaged. A single case report (McDougal et al., 1954) records the possibility of intrauterine infection but it seems unlike that herpes simplex virus can pass the placentaf barrier except by infecting it, and although this a possibility in case 3 , we take the view that in ouf cases the infection was transmitted from the mothe or attendants shortly after birth.

Unfortunately, there are no records of antibod titres in the infants before death, but we were abe to study the level of maternal antibody in one case (case 6) after the death of the infant. Here, a higझ titre of antibody was found and it would therefores be possible for significant transplacental transfer to have occurred. MacCallum (1959) too has noted that this condition may occur in spite of the presenç of maternal antibody. None the less the virus h\% multiplied in the liver apparently unchecked, pre? sumably either because the virus is for some reasote incapable of being neutralized by serum or, mo $\bar{\theta}$ probably, because, due to its intranuclear situatio the virus is out of reach of the antibody. An in portant spread of herpes virus has been demore 
strated from cell to cell on the chorioallantoic membrane of eggs (Wildy, 1954) away from the effects of antibody, and the virus of the liver may for this reason, too, be out of reach of maternal antibody until it has built up to an overwhelming concentration. In support of this view is the fact that recurrent herpes in adults does take place in spite of very high antibody titres, and Wheeler (1960) has shown that in Hela cell cultures neutralizing antibody neither prevented cell-to-cell spread of herpes virus nor did it eliminate the virus from the culture. Hoggan and Roizman (1959) also were able to isolate virus in the presence of antibody in tissue culture. Even so there is much evidence that a viraemia does occur. Previous authors (Ruchman and Dodd, 1950) have recorded recovery of the virus from the blood and we also have done this in case 3. Inclusion bodies have been found in organs such as the spleen and lymph nodes and are constantly present in the adrenal glands. This latter finding probably explains the sudden collapse and subsequent death of these infants, especially when the full extent of the infection in the adrenal is considered. At this point the analogy of the Waterhouse-Friederichsen syndrome occurs and it would be pertinent to suggest that perhaps the use of immune globulin and steroids might form a method of treatment. Before this can be undertaken, however. further study into the early symptoms of the disease and more precise methods of antemortem diagnosis are required.

We are indebted to Drs. G. S. Anderson, J. Hart-Mercer, and H. G. Kohler for allowing us to make use of their case records and to Professor C. A. Green for his helpful advice.

\section{REFERENCES}

Bird, T., and Gardner, P. S. (1959). Brit. med. J., 2, 993.

Colebatch, J. H. (1955). Med. J. Aust., 1, 377.

Cowdry, E. V. (1934). Arch. Path., 18, 527.

France, N. E., and Wilmers, M. J. (1953). Lancet, 1, 1181.

Hass, G. M. (1935). Amer. J. Path., 11, 127.

Hoggan, M. D,, and Roizman, B. (1959). Amer. J. Hyg., 70, 208

MacCallum. F. O. (1959). Acta virol. (Suppl.) 3, 17.

McDougal, R. A., Beamer, P. R., and Hellerstein, S. (1954). Amer. J. clin. Path., 24, 1257.

McKenzie, D., Hansen, J. D. L., and Becker, W. (1959). Arch. Dis. Childh., 34, 250.

Pugh, R. C. B., Newns, G. H., and Dudgeon, J. A. (1954). Ibid., 29, 60.

Quilligan, J. J., and Wilson, J. L. (1951). J. Lab. clin. Med., 38, 742.

Ruchman, I., and Dodd, K. (1950). Ibid., 35, 434.

Slavin, H. B., and Berry, G. P. (1943). J. exp. Med., 78, 321.

Wheeler, C. E. (1960). J. Immunol., 84, 394.

Wildy, P. (1954). Aust. J. exp. Biol. med. Sci., 32, 605.

Williams, A., and Jack, I. (1955). Med. J. Aust., 1, 392

Zuelzer, W. W., and Stulberg, C. S. (1952). Amer. J. Dis. Child., 83, 421 . 